\title{
CONTRASTING STORM IMPACTS ON GRAVEL BEACHES - EXAMPLES FROM SOUTH ENGLAND
}

\author{
Timothy Poate ${ }^{1,2}$, Robert McCall ${ }^{1}$, Gerd Masselink ${ }^{1}$, Paul Russell ${ }^{1}$, Mark Davidson ${ }^{1}$ \\ Topographic surveys are used to assess response characteristics of eight gravel beaches to storm conditions across \\ the south of England. Using profile volumes, pre- and post-storm, from surveys undertaken within a short temporal \\ interval a quantitative assessment of beach response to corresponding wave conditions has been undertaken. Wide \\ disparity in site response is found with contrasting accretionary and erosive behaviour observed un-correlated with \\ nearshore hydrodynamics. In addition predictive runup corresponds poorly with measured effective runup.
}

Keywords: gravel; storm response; runup; beach profile

\section{Introduction}

Gravel beaches and barriers are very common within England and Wales, extending along more than $1000 \mathrm{~km}$ of the coastline. They are widely regarded as a highly effective form of coastal defence due to the efficiency of dissipating wave energy, and help protect against overwashing and/or overtopping, and, therefore, coastal flooding. However, a recent DEFRA report has highlighted the increased pressure for coastal managers from storm damage and barrier breaching (DEFRA, 2008). Gravel beaches have received less attention than their sandy counterparts, resulting in a paucity of data on storm response. Due to the lack of detailed field data, current empirical models (Powell, 1990; Bradbury, 2000) remain the only source for coastal managers wanting to predict profile response.

In the UK more than $£ 357$ million was spent on coastal defence in 2007 with this figure expected to double by 2080 through recharge, recycling and reshaping practices to maintain current capabilities (DEFRA,

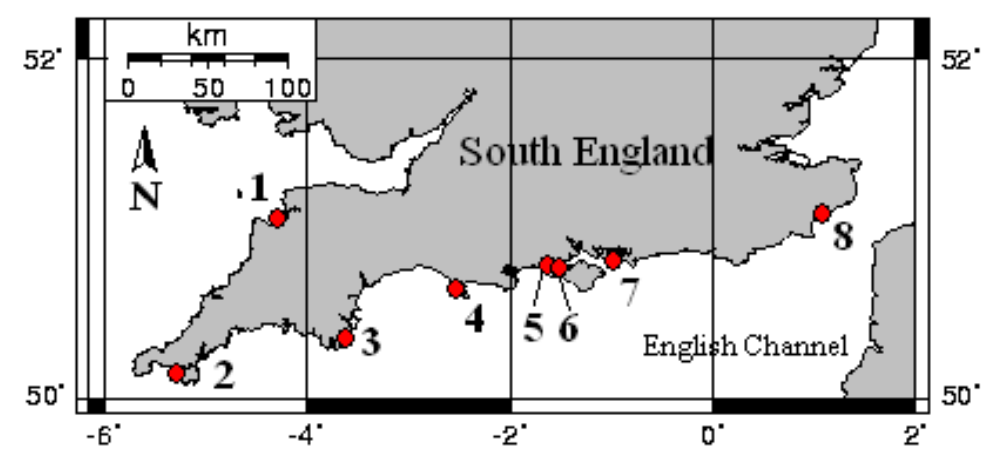
2010). With a high proportion of beaches in southern England being composed of mixed sand/gravel, fronting highly populated areas, the need for widespread engineering and management is clear (DEFRA, 2008).

Of particular interest to coastal managers is the increased likelihood of overwash/overtopping/breaching events which are expected to cause the greatest threat to coastal developments under storm events. The lack of detailed research and spatially/temporally coherent data for gravel sites means coastal managers lack suitable guidance on how best to manage and predict site specific response. Importantly, current runup formulae are primarily based on sandy sites (Stockdon et al., 2006) or lab measurements (Roberts et al., 2010) and may therefore limited in their application to gravel sites.

In this paper we present the profile response from eight gravel barriers and beaches, located across the south of the UK (Figure 1), to extreme storm events. The sites have been chosen as part of a project which aims to develop New Understanding and Prediction of Storm Impacts on Gravel beaches (NUPSIG) being undertaken by Plymouth University. The range of sites provides a detailed assessment of site-specific response (from different storms) and comparative analysis from multiple sites during a single storm event. The paper also addresses the importance of data collection for pre-storm and poststorm measurements. Current policy by beach managers focuses on post-storm analysis of beach response; however, the importance of a recent reference or baseline profile is emphasised. Indeed, it

\footnotetext{
${ }^{1}$ Plymouth University, Plymouth, Devon, PL4 8AA, United Kingdom

2 timothy.poate@plymouth.ac.uk
} 
will be demonstrated and argued that for many cases a post-storm survey is of very limited use if an appropriate pre-storm profile is not available.

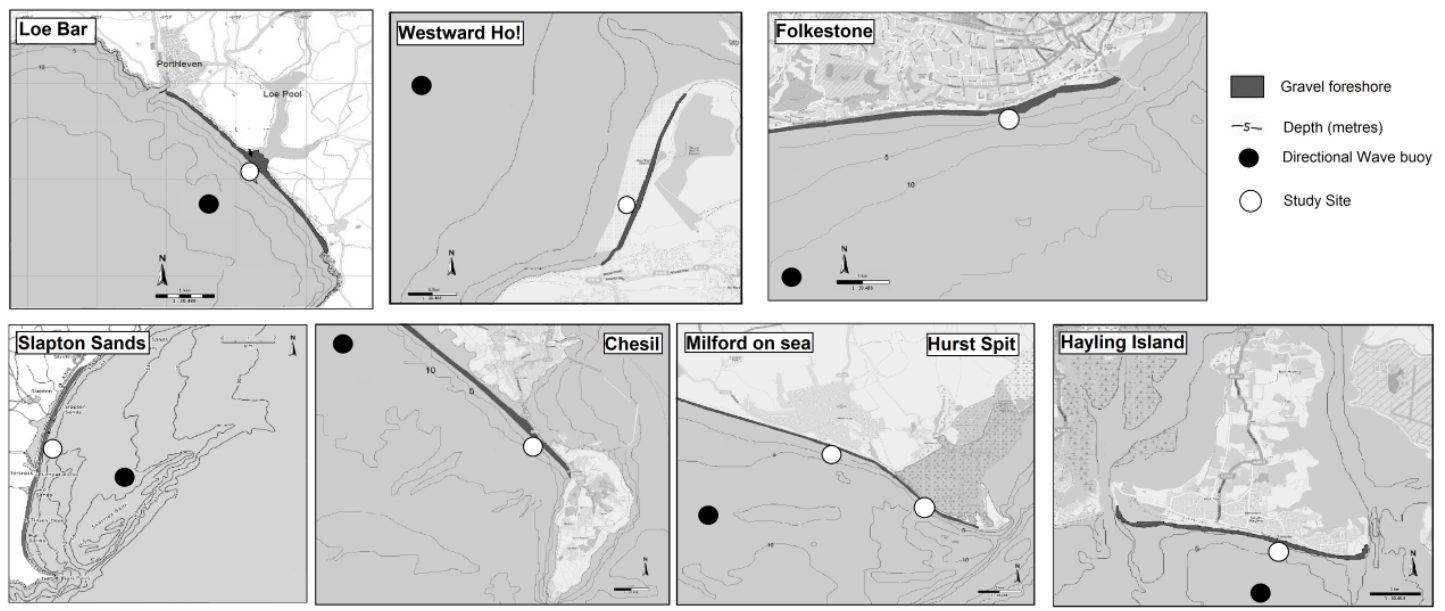

Figure 3. Detailed maps of eight study sites used within this paper as presented in Figure 1. The location of nearshore directional wave buoys are indicated along with gravel foreshore and study locations. The numbers refer to the locations shown in Figure 1.

\section{Method}

The work presented in this paper is based on topographic surveys carried out at the sites presented in Figure 2. In each case topographic surveys were undertaken using real-time kinematic GPS prior to and post storm events at each beach. This work was carried out by field personnel at Plymouth University (Loe Bar, Slapton and Westward Ho!) and by the Channel Coastal Observatory (CCO) who have undertaken beach surveys since 2006. The alongshore interval of the profile lines varied between sites but was approximately 50-100 m for most sites with 10-20 profiles routinely measured. Storms were defined using a peaks-over-threshold approach whereby a wave event was classed a storm when the hourly averaged significant wave height $\left(H_{s}\right)$ exceeds a threshold value previously defined based on previous wave conditions and local knowledge of the site. Where possible, pre-storm and post-storm surveys were undertaken within a small window of the storm event, although adverse tide and weather conditions can inhibit this.

Profile analysis was undertaken by computing the profile change using the volumetric difference between successive surveys for each transect $\left(\mathrm{m}^{3} \mathrm{~m}^{-1}\right)$. Profile volume was calculated over four regions by integrating the profile upwards from mean low water springs to mean sea level (MSL), from MSL up to mean high water springs (MHWS), from MHWS to MHWS+2 m and from MHWS+2 to the top of the profile. This provided the lower intertidal (LI), upper intertidal (UI), lower supratidal (LS) and upper supratidal (US) volumes for each transect (Figure $2)$. For surveys where the full profile did not extend beyond MLWN the LI was omitted; however, it was usually possible to extend the profiles through extrapolation to extend the coverage.

On several beaches 3D topographic surveys were undertaken using RTK-GPS mounted on an all-terrain vehicle (ATV). Beach elevation was

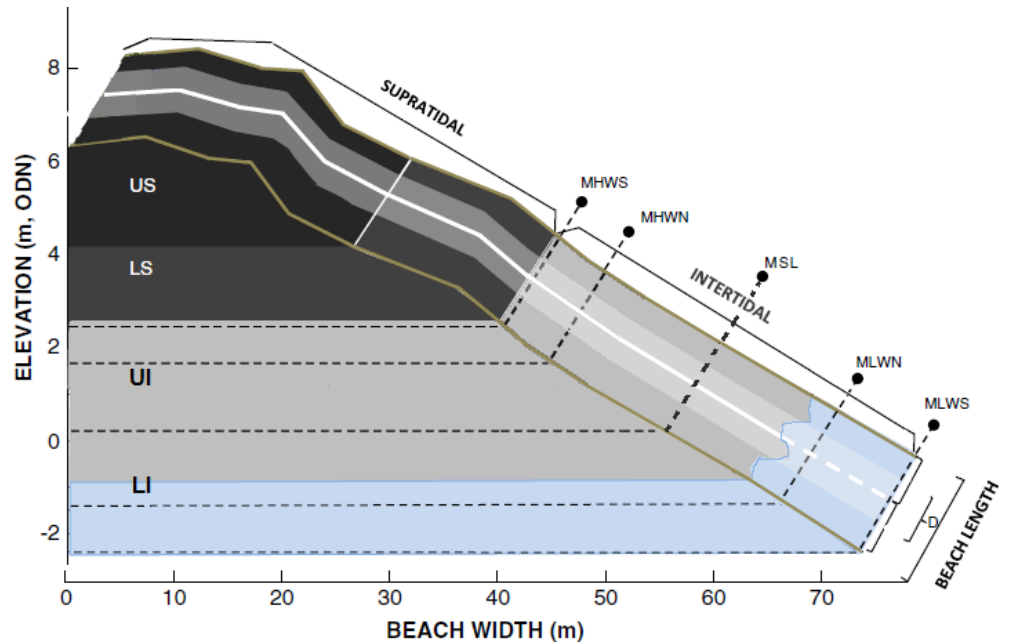

Figure 2. Schematic diagram of a cross-shore profile illustrating the method used to compute beach volume for different section of the profile (see text; adapted from Ruiz de Alegria-Arzaburu et al. (2010)). 
logged continuously as the ATV covered an irregular grid across the beach face covering both cross and longshore lines at $\sim 10-15 \mathrm{~m}$ spacing. These data points were then interpolated onto a regular $1 \mathrm{x} 1 \mathrm{~m}$ grid using a loess interpolation routine best suited to irregular data collection (Plant et al., 2008).

The effective run-up position $\left(R_{m}\right)$ was computed by identifying the point of divergence between the pre- and post-storm profiles, moving seaward from the back of the beach down to the maximum tidal elevation during the storm period. The vertical runup was then compared with the empirical extreme runup parameterisation $R_{2}$ presented by Stockdon et al., (2006);

$$
R_{2}=1.1\left(0.35 \beta_{f}\left(H_{0} L_{0}\right)^{1 / 2}+\frac{\left[H_{0} L_{0}\left(0.563 \beta_{f}^{2}+0.004\right)\right]^{1 / 2}}{2}\right)
$$

where $\beta_{f}$ is the profile slope, $L_{0}$ is the deep water wave length and $H_{0}$ is the deep water wave height (m). For both the $R_{2}$ and $R_{m}$ an average was generated using all profiles available for each site and each storm.

At each site, nearshore directional Datawell Waveriders ${ }^{\circledR}$ owned and maintained by the Channel Coastal Observatory are present (Figure 2) and their data were used to provide wave conditions throughout the survey period. The wave buoys form a national network of nearshore wave measurements and are moored in $10 \mathrm{~m}$ water depths providing wave stats in real-time on a half hourly basis (www.channelcoast.org).

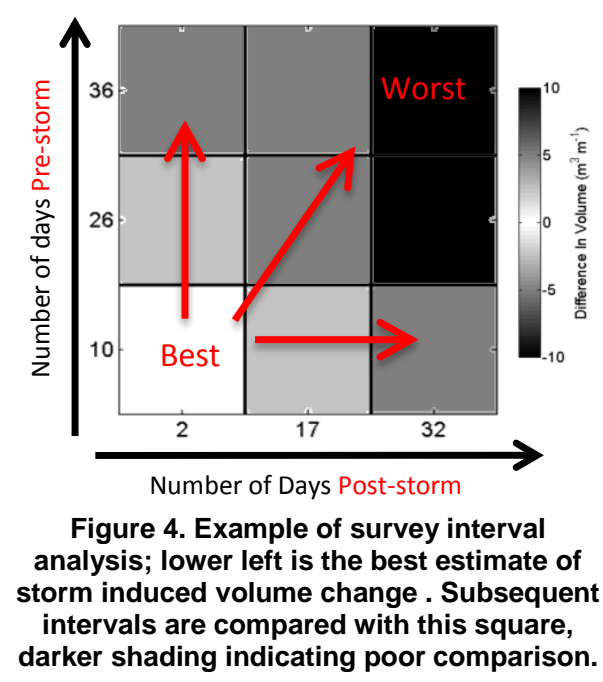

\section{Results}

\section{Survey Interval}

Archived topographic survey data collected by $\mathrm{CCO}$ and more recent surveys collected under the NUPSIG project were collated to build a database of storm events across the eight sites. A total of 184 storm events were identified dating back to 2005 with only 44 events undergoing a post-storm survey. Of the sites included, Slapton Sands has benefited from the greatest temporal resolution with poststorm surveys undertaken in addition to regular fortnightly surveys. This dataset provides the opportunity to assess the impact of survey interval on the evaluation of storm response. By defining the shortest survey interval around a storm as the best representation of that storms response we are able to compare how the results differ if the survey interval is made longer through earlier pre-storm surveys or later post-storm surveys (Figure 4). As in the example, lighter shading indicates a close result and darker shading highlights strong differences in the profile volumes. 


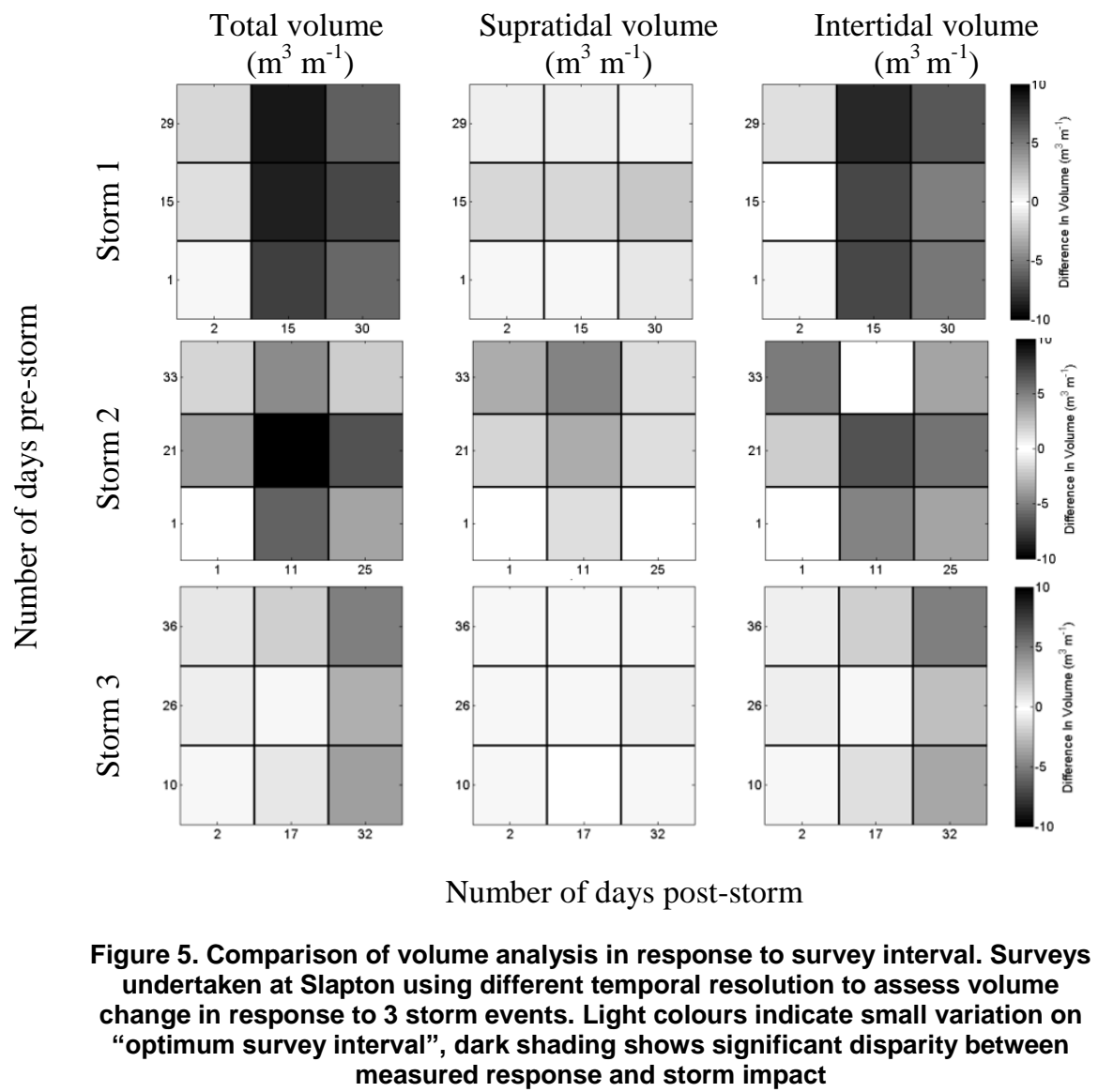

Figure 5 shows the results for three separate storm events; for each section of the profile the volume was calculated (total, supratidal and intertidal) with the lower left of each grid representing the smallest survey interval and therefore the "best" measure of storm impact. For each of the storms the supratidal region varies little in response to the survey interval, which is what we would expect provided there were no larger storms within the survey period. The intertidal regions however show greater disparity which subsequently affects the total profile calculations. The further from the shortest survey interval the greater the difference in profile volume however we also see some cases where the results suggest a similar output despite reduced temporal resolution (Figure 5). Whilst Figure 5 highlights the importance of post-storm surveys immediately following a storm having the greatest impact on volume calculations ( $>5 \mathrm{~m}^{3} \mathrm{~m}^{-1}$ difference) before recover conditions affect profile shape, reliable pre-storm data also impacts on overall quantification of the response analysis. As will be discussed further storm sequencing plays a significant role in profile response, and further complicates analysis where survey interval is insufficient to resolve individual storm impacts sufficiently. 


\begin{tabular}{|c|c|c|c|c|c|c|c|c|c|c|c|}
\hline \multirow{2}{*}{ Site Name } & \multirow{2}{*}{ Year } & \multirow{2}{*}{$\begin{array}{l}\text { Date of } \\
\text { Storm }\end{array}$} & \multirow{2}{*}{$\mathbf{H}_{\mathrm{s}}$} & \multirow{2}{*}{$T_{p}$} & \multirow{2}{*}{ Dir } & \multicolumn{3}{|c|}{\begin{tabular}{|c|} 
Mean Profile Volume Change \\
$\qquad\left(\mathrm{m}^{2} \mathrm{~m}^{-1}\right)$
\end{tabular}} & \multirow{2}{*}{$\begin{array}{c}\text { Measured } \\
\text { Runup } \\
\mathbf{R}_{\mathrm{m}(\mathrm{m})}\end{array}$} & \multirow{2}{*}{$\begin{array}{l}\text { Predicted } \\
\text { Runup } \\
\mathbf{R}_{\mathbf{2}(\mathbf{m})}\end{array}$} & \multirow{2}{*}{$\begin{array}{l}\text { Tide stage } \\
\text { ref. HW }\end{array}$} \\
\hline & & & & & & Total & Supratidal & Intertidal & & & \\
\hline Chesil & 2009 & $14 / 11 / 2009$ & 6.95 & 12.5 & 229 & -16 & -14.95 & -1.12 & 8.38 & 6.54 & -5 \\
\hline Folkestone & 2007 & $08 / 12 / 2007$ & 2.86 & 7.7 & 183 & -4.66 & -2.23 & -2.42 & 2.22 & 1.76 & -6 \\
\hline $\begin{array}{l}\text { Hayling } \\
\text { Island }\end{array}$ & 2005 & $03 / 11 / 2005$ & 3.33 & $\mid 18.2$ & 200 & -6.39 & -10.62 & 4.22 & 3.08 & 3.57 & +1 \\
\hline $\begin{array}{l}\text { Hayling } \\
\text { Island }\end{array}$ & 2010 & $08 / 11 / 2010$ & 3.25 & 7.7 & 187 & 5.55 & 2.16 & 3.38 & 1.14 & 1.51 & -3 \\
\hline $\begin{array}{l}\text { Hayling } \\
\text { Island }\end{array}$ & 2011 & 23/10/2011 & 2.21 & 7.10 & 156 & 0.15 & -1.82 & 1.97 & 2.66 & 1.21 & N/A \\
\hline Hurst & 2006 & $03 / 12 / 2006$ & 3.51 & 10 & 218 & -6.06 & -7.40 & 1.34 & 2.76 & 3.52 & -2 \\
\hline Hurst & 2007 & $18 / 01 / 2007$ & 3.64 & 11.1 & 214 & 0.97 & 0.95 & 0.02 & 4.53 & 3.11 & -2 \\
\hline Hurst & 2008 & $10 / 03 / 2008$ & 3.42 & 18.2 & 217 & 1.46 & 1.26 & 0.20 & 3.15 & 4.50 & -4 \\
\hline Hurst & 2009 & $14 / 11 / 2009$ & 4.08 & 11.8 & 214 & -8.83 & -9.37 & 0.54 & 3.15 & 4.06 & -6 \\
\hline Hurst & 2011 & $12 / 09 / 2011$ & 2.07 & 7.10 & 215 & -2.20 & -3.08 & 0.88 & 2.42 & 2.02 & -1 \\
\hline Hurst & 2011 & $29 / 10 / 2011$ & 1.67 & 18.0 & 205 & -2.21 & -3.25 & 1.04 & 2.47 & 4.18 & +4 \\
\hline Loe Bar & 2008 & $10 / 03 / 2008$ & N/A & N/A & N/A & -27.2 & -21.05 & -6.17 & 4.32 & N/A & N/A \\
\hline Loe Bar & 2011 & $15 / 01 / 2011$ & N/A & N/A & N/A & -3.41 & -2.49 & -0.92 & 4.29 & $\mathrm{~N} / \mathrm{A}$ & N/A \\
\hline Loe Bar & 2011 & $12 / 09 / 2011$ & 3.2 & 12.5 & 245 & 3.10 & 1.14 & 1.97 & 3.48 & 2.72 & -2 \\
\hline Loe Bar & 2011 & $03 / 11 / 2011$ & 4.03 & 18 & 241 & 7.24 & 2.66 & 4.58 & 6.18 & 4.25 & +4 \\
\hline Loe Bar & 2011 & $13 / 12 / 2011$ & 5.03 & 12.5 & 232 & 16.5 & 14.57 & 1.94 & 5.56 & 3.30 & HW \\
\hline Loe Bar & 2012 & $02 / 01 / 2012$ & 5.5 & 12.0 & 240 & -16.7 & -15.35 & -1.37 & 5.45 & 3.40 & -3 \\
\hline Milford & 2010 & 08/11/2010 & 2.60 & 7.70 & 205 & -1.15 & -1.88 & 0.72 & 2.45 & 1.98 & -4 \\
\hline Slapton & 2007 & $18 / 11 / 2007$ & 3.21 & 8.30 & 169 & 1.52 & -0.28 & 1.80 & 2.33 & 1.98 & +3 \\
\hline Slapton & 2008 & $13 / 01 / 2008$ & 3.49 & 8.30 & 153 & 0.39 & 0.35 & 0.04 & 2.64 & 1.98 & -3 \\
\hline Slapton & 2008 & $03 / 02 / 2008$ & 3.20 & 8.30 & 153 & 0.50 & -0.11 & 0.61 & 2.94 & 2.04 & -1 \\
\hline Slapton & 2008 & $\begin{array}{c}10 / 03 / 2008 \\
04: 30 \\
\end{array}$ & 3.17 & 9.10 & 176 & 0.81 & 1.51 & -0.70 & 2.87 & 2.14 & -2 \\
\hline Slapton & 2008 & $17 / 04 / 2008$ & 3.94 & 9.10 & 96 & 0.85 & -4.62 & 5.47 & 3.30 & 2.38 & +4 \\
\hline Slapton & 2008 & $13 / 12 / 2008$ & 2.54 & 7.70 & 177 & -1.39 & 0.08 & -1.48 & 2.78 & 1.79 & +4 \\
\hline Slapton & 2009 & $01 / 02 / 2009$ & 3.36 & 8.30 & 97 & 4.01 & -1.81 & 5.81 & 2.49 & 2.00 & HW \\
\hline Slapton & 2009 & $14 / 11 / 2009$ & 3.26 & 10 & N/A & -4.24 & -2.50 & -1.74 & 2.87 & 2.49 & +2 \\
\hline $\begin{array}{c}\text { Westward } \\
\text { Ho! }\end{array}$ & 2011 & $13 / 09 / 2011$ & 4.39 & $\mid 14.3$ & 281 & -2.49 & -0.20 & -2.29 & 2.38 & 4.04 & -2 \\
\hline $\begin{array}{c}\text { Westward } \\
\text { Ho! }\end{array}$ & 2011 & 30/10/2011 & 3.2 & 18.2 & 287 & 4.95 & 1.06 & 3.89 & 1.89 & 4.24 & -2 \\
\hline $\begin{array}{l}\text { Westward } \\
\text { Ho! }\end{array}$ & 2011 & |13/12/2011 & 6 & 22.0 & 280 & 0.78 & 0.25 & 0.53 & 1.90 & 7.32 & -4 \\
\hline
\end{tabular}

\section{Storm Response}

Using the analysis undertaken on the Slapton Sands dataset and to maximise the number of events, the storms examined were limited to those where the survey interval was less than 30 days with the post-storm survey being undertaken within three days (Table 1). A summary of each site including overall profile behaviour is followed by more detailed assessment for specific storm events identifying alongshore variability, where present, and volume changes. 
The single storm logged at Chesil was a large $\left(6.95 \mathrm{~m} \mathrm{H}_{s}\right)$ long period event $\left(12.5 \mathrm{sec} T_{p}\right)$ which occurred in 2009. Overall net loss was experienced across the site (Table 1) which is evident in the example profile in Figure 6a whereby material was shifted from the upper supratidal to the lower intertidal. A similar cut and fill profile response was observed at Folkestone in 2007, although the pivot point was centred around MSL (Figure 6b). With only one storm at both sites we are not able to compare these events with others for the same site to establish response trends. At Hayling Island 3 storms occurred in 2005, 2010 and 2011 (Table 1) with wave conditions ranging from 2.2 to $3.3 \mathrm{~m}$ with net loss of profile volume occurring under long period waves ( $>18 \mathrm{~s} T_{p}$ ) during the storm of 2005 . The profile response was characterised by a removal of berm features and a flattening of the profile (Figure 6c). In 2010 a net increase in volume occurred under energetic waves, which was evident in the buildup of material at the top of the profiles.
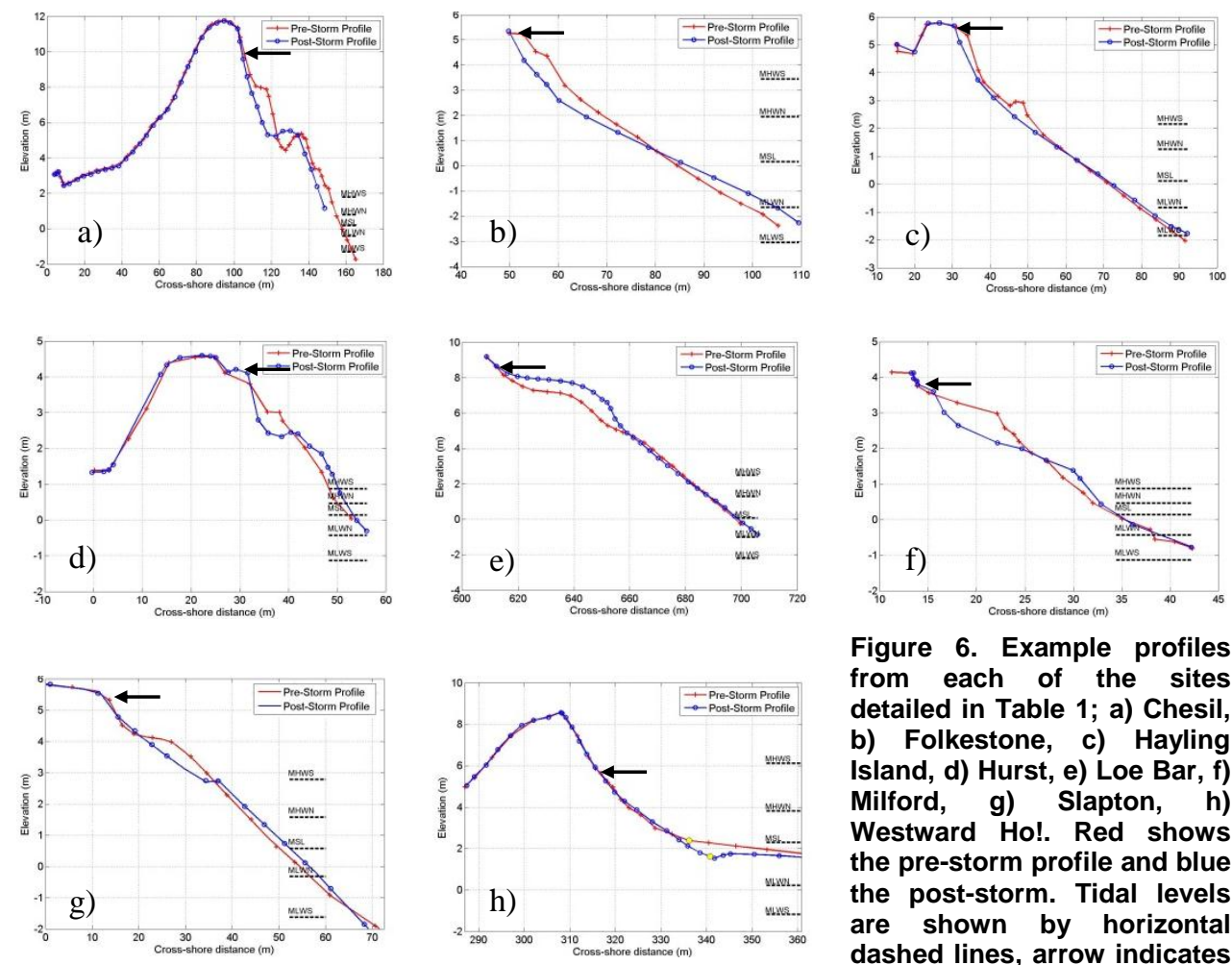

Figure 6. Example profiles from each of the sites detailed in Table 1; a) Chesil, b) Folkestone, c) Hayling Island, d) Hurst, e) Loe Bar, f) Milford, g) Slapton, h) Westward Ho!. Red shows the pre-storm profile and blue the post-storm. Tidal levels are shown by horizontal dashed lines, arrow indicates point of effective runup $\left(R_{m}\right)$.

Hurst provides one of the longest records of the sites, although the managed nature of the driftaligned spit which undergoes recharge and re-profiling should be considered when comparing with other sites. The results in Table 1 highlight the variability in results with a range of accretion and erosion responses following energetic storms with a range of wave periods. Overall, the profile behaved in a similar manner to other sites with smoothing of morphological features and removal of material from the upper beach face towards the lower profile (Figure 6d). Loe Bar has become one of the key sites in this study and as such has more recent storm surveys undertaken (as will be discussed further below). Again we see a mix of accretionary and erosive response under energetic waves (Table 1). The accretionary events (through 2011) experienced similar profile shifts to that shown in Figure 6e with maximum accretion well above MHWS. The importance of storm sequencing will be discussed further later with regard to Loe Bar. The response at Milford again follows other sites with removal of profile features and smoothing of the beachface with a small net loss of beach volume. Slapton experiences storms from two dominant directions (Ruiz de Alegria-Arzaburu et al., 2010) and therefore the response between profiles can be varied dependant on wave approach and storm sequencing. With longshore movement of material within the bay the storm response is dependent on the preceding conditions and the antecedent morphology (cf., Ruiz de Alegria-Arzaburu et al., 2010). Measurements at Westward Ho! are made more complex by the size of the boulders at this site $(>0.3 \mathrm{~m})$ which has a bearing on profile measurements. In addition the wide highly planar sandy beach which extends from the toe of the cobble barrier at $\sim$ MSL makes this site distinct from those discussed above. The principle 
response observed during storm events in 2011 were the removal of berm features present on the upper profile and removal of sand from the toe of the barrier (Figure 6h).

The following section focuses on some of the sites listed above and provides comparison of profile response under storm events. In each case the wave conditions are presented as well as the individual profile response broken down into the total profile, the supratidal and the intertidal volume change.

Analysis of the storm response at Hurst under two storm events in 2011 is presented in Figure 7 and shows very similar results in terms of individual profile response across the site. As outlined above, we see a dominance of material being removed from the supratidal section of the beach face and deposited in the intertidal lower areas. Neither of the storms were particularly significant and, in fact, both were preceded by waves of similar magnitude. However, despite the conditions the profiles still underwent sediment loss from the upper beachface. Despite the drift alignment of the spit, the profile response for the storms presented does not highlight a significant alongshore trend in profile change and was remarkably longshore-uniform.

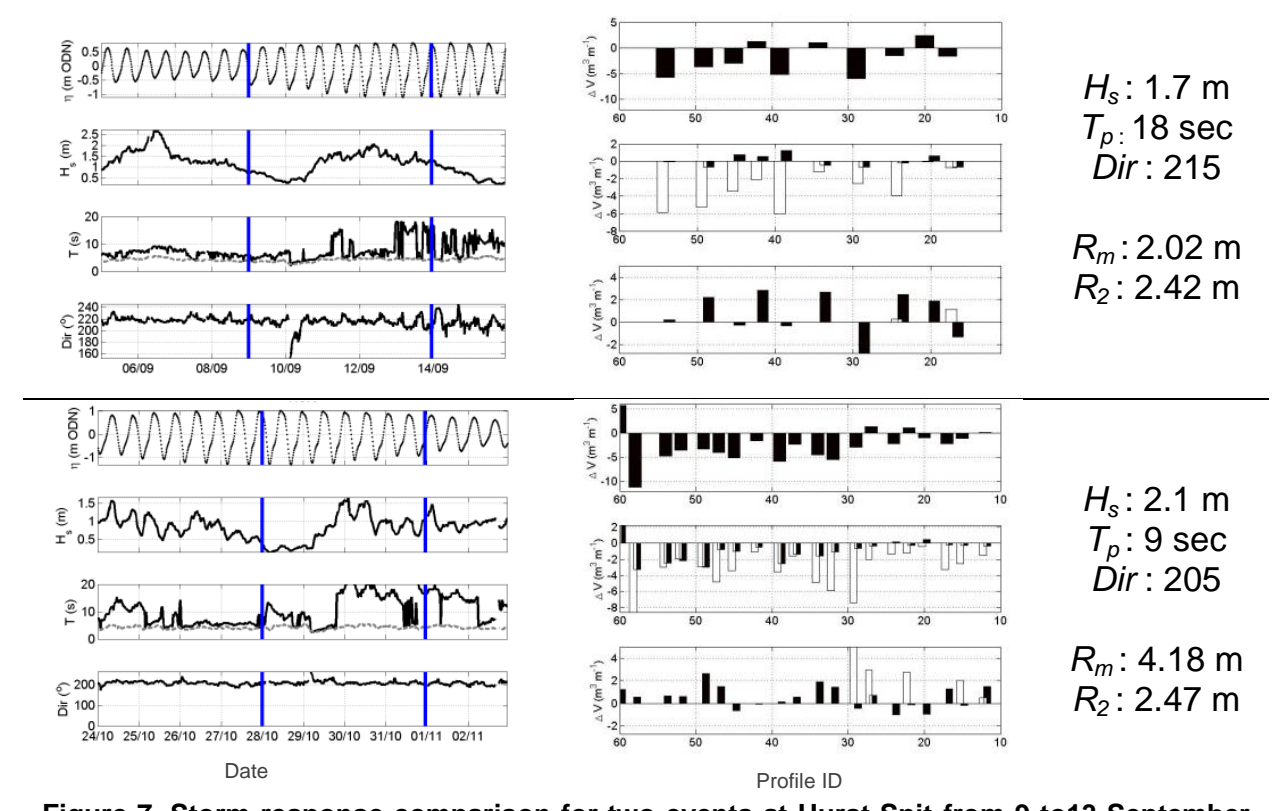

Figure 7. Storm response comparison for two events at Hurst Spit from 9 to13 September 2011 (top) and from m28 to31 October 2011 (bottom). The left panels shows the tide state, $H_{s}(\mathrm{~m}), T_{p}(\mathrm{sec})$ and wave direction (deg); the right panels shows the change in total individual profile volume (upper plot), supratidal (US = black, LS = white) and intertidal (UI $=$ black, $\mathrm{LI}=$ white). Summary wave stats and runup measurements $\left(\boldsymbol{R}_{m}\right)$ and prediction $\left(\boldsymbol{R}_{2}\right)$ are included to the right. Alongshore profile spacing $\sim 50 \mathrm{~m}$.

The response we see at Hayling Island for two similar storms was markedly different (Figure 8). Under energetic waves in November $2011\left(H_{s}>3.2 \mathrm{~m}\right)$ each of the profiles measured experienced a net increase in total volume up to $10 \mathrm{~m}^{3} \mathrm{~m}^{-1}$ for both the lower supratidal and the upper intertidal (Figure 8; top panels). The profile response during an earlier storm in October 2011, on the other hand, resulted in a more mixed response with clear shifts in volume down the profile (Figure 8; bottom panels). The first storm was a short period event under spring tides with surveys within a few days of each other, the second event was less intense and the survey interval was greater. 


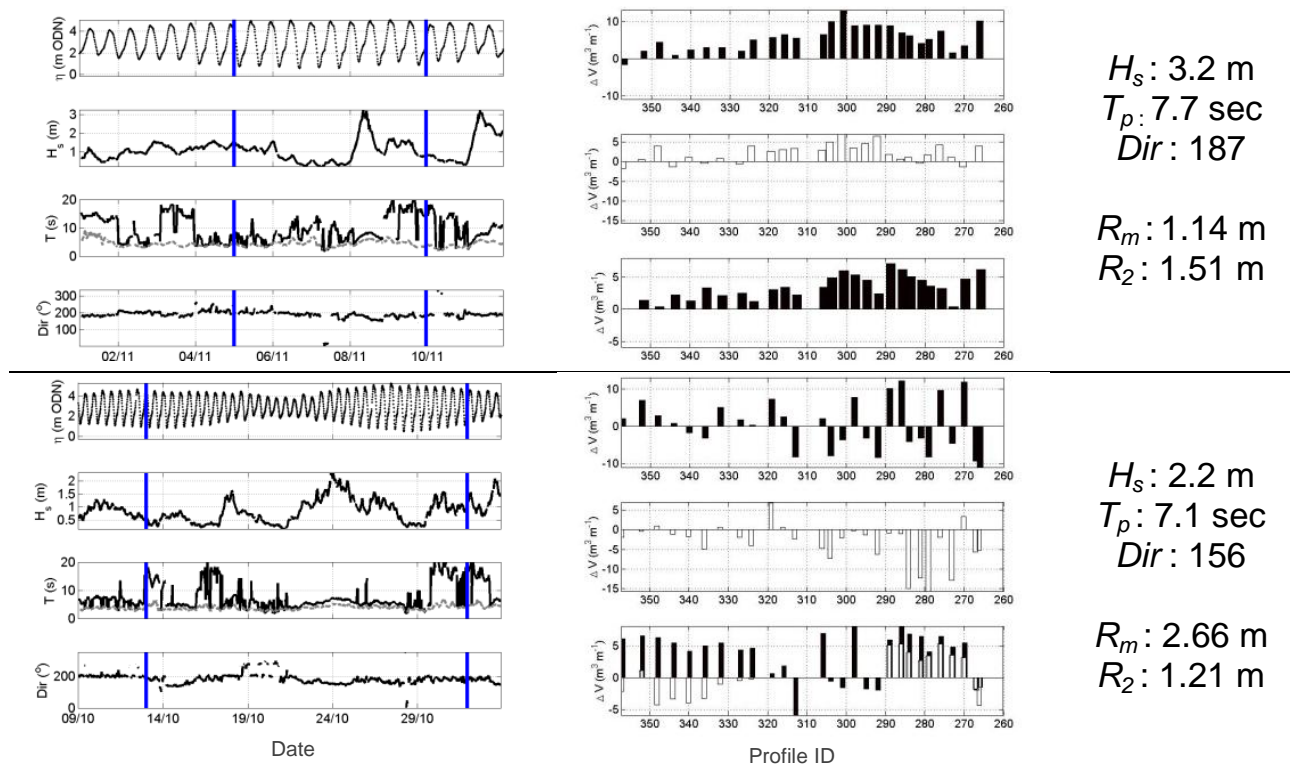

Figure 8. Storm response comparison for two events at Hayling Island from $\mathbf{5}$ to $\mathbf{9}$ November 2010 (top) and from 13 to 31 October 2011 (bottom). The left panels shows the tide state, $H_{s}$ $(\mathrm{m}), T_{p}(\mathrm{sec})$ and wave direction (deg); the right panels shows the change in total individual profile volume (upper plot), supratidal (US = black, LS = white) and intertidal (UI = black, LI = white). Summary wave stats and runup measurements $\left(R_{m}\right)$ and prediction $\left(R_{2}\right)$ are included to the right. Alongshore profile spacing $\sim 50 \mathrm{~m}$.

The two storms experienced at Loe Bar presented in Figure 9 provide highly contrasting responses evident in both the individual profiles and the surface plots (Figure 10). The first storm occurred in mid-December and was characterised by sustained energetic waves $>4 \mathrm{~m} H_{s}$ while the second storm was a much shorter more intense event preceded by calm conditions following the previous storm (Figure 9). The first event occurred during spring tides and resulted in widespread accretion above MHWS, the second storm occurred under neap conditions leading to widespread loss across the beach face (Figure 10). Differences in profile response were evident towards the edge of the survey area where the beach narrows due to steep cliffs affecting the profile shape in these areas.

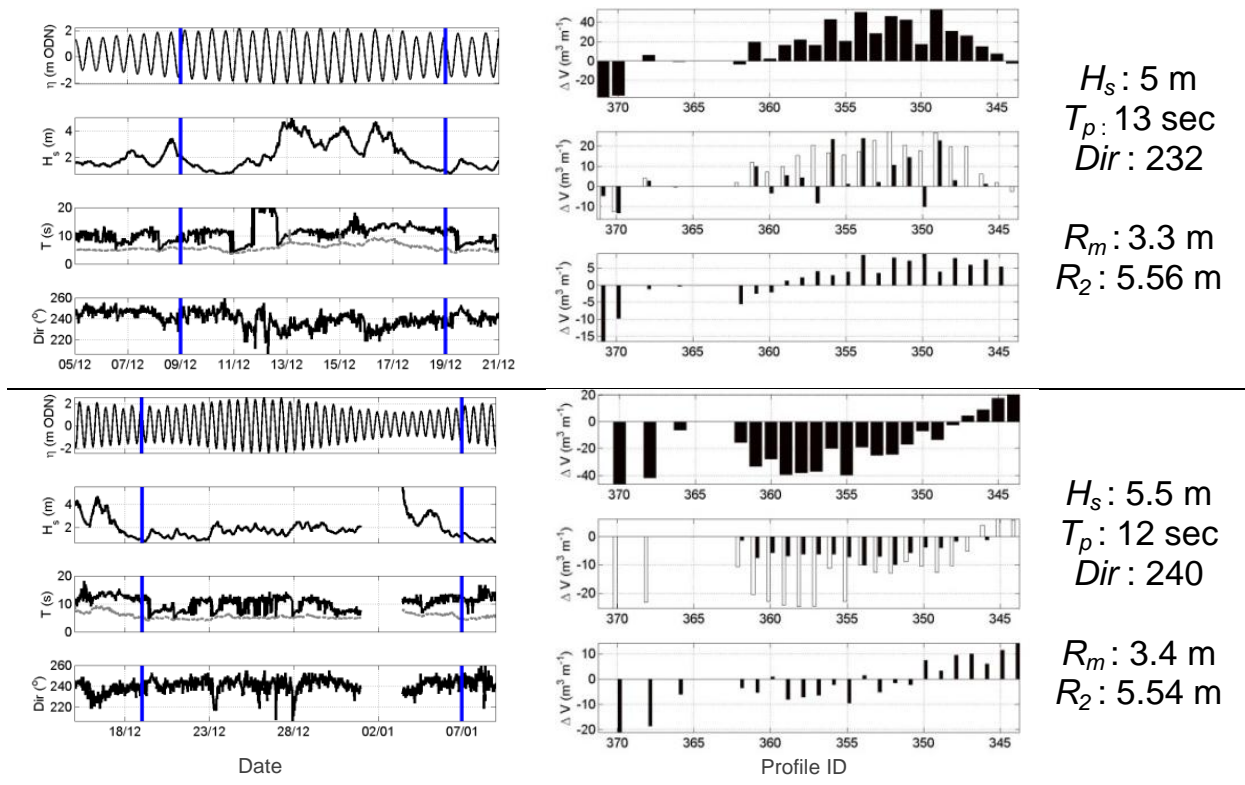

Figure 9. Storm response comparison for two events at Loe Bar the $9^{\text {th }}-19^{\text {th }}$ December 2011 (top) and the $19^{\text {th }}$ December $-6^{\text {th }}$ January 2012 (bottom); the left panels shows the tide state, $H_{s}(\mathrm{~m}), T_{p}(\mathrm{sec})$ and wave direction (deg); the right panels shows the change in total individual profile volume (upper plot), supratidal (US = black, LS $=$ white) and intertidal (UI $=$ black, $\mathrm{LI}=$ white). Summary wave stats and runup measurements $\left(R_{m}\right)$ and prediction $\left(R_{2}\right)$ are included to the right. Alongshore profile spacing $\sim 50 \mathrm{~m}$. 
The 3D nature of Loe Bar restricts the analysis of individual profiles due to the large cuspate features present across the beachface. The 3D surface plots highlight the growth of the cusp horns following the first storm and this representing much of the accretion that occurred. These horns were then removed during the second storm (Figure 10). Although the survey interval for the second storm is greater, it is unlikely that the small waves during this time would have had any impact on the deposits from the previous storm and we can be fairly confident that the erosion was in response to the short storm event on the $3^{\text {rd }}$ January.
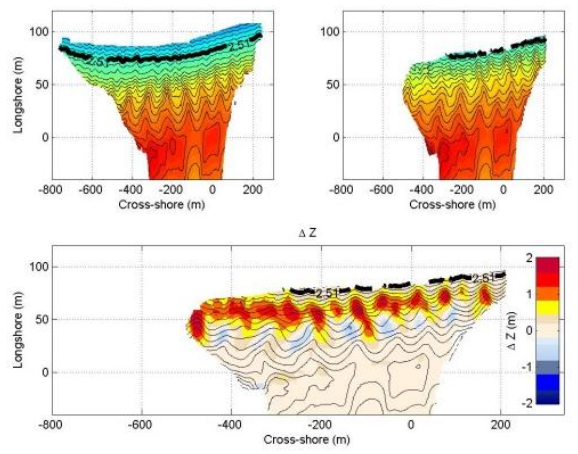
Figure 10. 3D surface plots from Loe Bar. The bottom two plots show the elevation change
between the upper surfaces for the period from 9 to 19 December (left panel) and from 19 December to 6 January (right panel). Red and blue colours indicate accretion and erosion, respectively, and the thick black contours identifies MHWS.

\section{Discussion}

The summary of storm events and the morphological responses presented in Table 1 provide a clear overview of the variability in response both between different sites and at the same site during different storms. Combined with nearshore wave data, significant trends and thresholds of response are difficult to define based on the small selection of storms for which data are available. The occurrence of net erosive events (as indicated by the dark shading in Table 1) is balanced by net accretive responses however both Table 1 and the profile shape responses evident in Figure 6 suggest a slight dominance of the cut and fill shift in material from the upper (suprtidal) to the lower (intertidal) regions. It is likely that the greatest chance of overwashing/overstopping would occur as peak storm waves coincide with high water, however, Table 1 shows no evidence for a relationship between the tidal stage and the net profile response for any site.

Figure 11 builds on Table 1 by providing a graphical summary of the storm responses at each site. This plot further highlights the variability in profile response under different wave heights and periods. Of particular interest are the number of storm events where the net profile response is positive, which is contrary to our expected understanding of profile behaviour. With restricted coverage at most sites for either pre- or post-storm surveys, not all profiles extend fully to MLWS and therefore some information on sediment shifts may have been missed. Equally, alongshore patterns in sediment transport are difficult to extract from individual profiles at $>50 \mathrm{~m}$ intervals especially where active management in the form of groynes/sea defences are in place. 

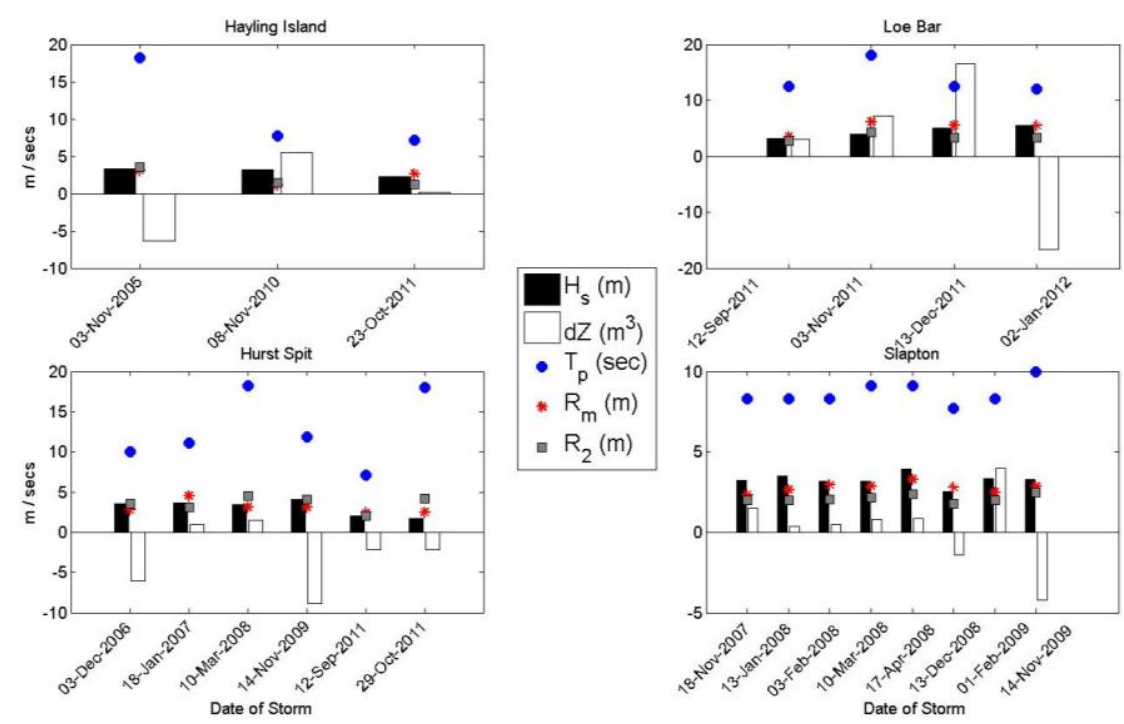

Figure 11. Storm summaries for four sites including wave conditions $\left(H_{s} T_{p}\right)$, profile response (dZ) and runup positions $\left(\boldsymbol{R}_{m}, \boldsymbol{R}_{2}\right)$.

At Hayling Island local reports state the long period event in 2005 caused overtopping (and erosion) compared with the subsequent shorter period events of similar wave heights where accretion occurred (Figure 11). Hurst provides a contrasting dataset of long period events of similar wave heights causing both erosive and accretionary profile responses. The most consistent response of all the sites was observed at Slapton. The south easterly facing sites means it is protected from the larger south westerly storms and as such it is usually affected by shorter period local wind seas providing consistency in the wave climate, although the profile response in 2009 was highly contrasting.

The role of storm sequencing on sites is also a large factor on the individual storm impact. At Loe Bar the four storms presented occurred between September 2011 and January 2012 with a steady rise in wave height which was matched by levels of accretion before the final storm which saw significant loss (Figure 11). As wave conditions increase under more energetic winter weather patterns there is an argument the beach will move towards an equilibrium state under the dominant conditions; however, this would suggest initial storms would have greater impact on the profile shape than latter storms of equal size, which does not appear to have occurred at Loe Bar (Figure 11).

By comparing two profiles and identifying the "effective" runup $\left(R_{m}\right)$ position we can compare this to the empirical extreme runup parameterisation $\left(R_{2}\right)$ as proposed by Stockdon et al., (2006). This formulation has been developed based on video runup data collected on sandy beaches and has not been applied to gravel beaches, and it is worth testing its suitability. Figure 11 shows the $R_{2}$ with the $R_{m}$ showing for Slapton and Loe Bar the $R_{2}$ consistently under predicts the measured runup point, whereas the results are more mixed at Hayling Island and Hurst.

2D profiles are a ubiquitous feature of beach monitoring and while they are often restricted in crossshore extent, below MLWS, they provide a valuable cost effective tool for assessment of beach response. Where available 3D surveys add to the interpretation, especially alongshore variability, although this approach does not offer more low tide coverage. The importance of cross shore transport on gravel beaches, specifically step dynamics, identifies the importance of this region to a complete understanding of the storm response (Masselink et al., 2010). Without this coverage the data presented highlights the disparity between sites and between separate storms at the same site.

\section{Conclusions}

Using measured topographic profiles in connection with nearshore wave data a summary of significant storm events at a selection of gravel sites across southern England have been presented. From eight sites and 184 separate storm events in the last five years 29 events have been assessed for their storm response. Using profile volume, wave conditions and runup measurements response characteristics have varied for individual sites and between sites. There is little evidence, from the dataset available, to define thresholds of change or levels of response. Contrasting erosive and accretive storms compound these findings and further highlight the significant lack of understanding we have for the numerous gravel beaches across England. Current runup prediction parameters provide poor 
correlation with measured effective runup posing a real concern for the prediction of overtopping events which can lead to coastal flooding.

Further understanding of storm impacts will only be possible through specific targeted measurements of hydrodynamics and morphology under storm conditions at a range of sites. If achieved the data presented here may well be revisited and incorporated into the development of models for gravel beaches.

\section{Acknowledgements}

This work was funded by EPSRC grant EP/H040056/1 in partnership with the Channel Coastal Observatory (CCO), HR Wallingford and The Environment Agency. Field surveys were undertaken by Plymouth University and $\mathrm{CCO}$ as part of the regional monitoring program.

\section{References}

Austin, M. J. \& Masselink, G. (2006) 'Observations of morphological change and sediment transport on a steep gravel beach', Marine Geology, 229 (1-2), pp. 59-77

Bradbury, A., 2000. Predicting breaching of shingle barrier beaches-recent advances to aid beach management, Proceedings of 35th Annual MAFF Conference of River and Coastal Engineers.

DEFRA, 2008. Understanding barrier beaches. R\&D Technical Report FD1924/TR

DEFRA (2010), Charting Progress 2 The State of UK seas. pp166. http://chartingprogress.defra.gov.uk/.

Masselink, G., P. Russell, et al. (2010). "Swash zone sediment transport, step dynamics and morphological response on a gravel beach." Marine Geology 274(1-4): 50-68.

Plant, N. G., K. Holland, T., et al. (2008). "Application of quadratic loess filters to bathymetric interpolation."

Powell, K.A., 1990. Predicting Short Term Profile response for shingle beaches. Report SR 219, HR Wallingford, Oxfordshire, UK.

Roberts, T.M, Wang, P, Kraus, N.C (2010) 'Limits of Wave Runup and Corresponding Beach-Profile Change from Large-Scale Laboratory Data' Journal of Coastal Research 26 (1), pp184-198.

Ruiz de Alegria-Arzaburu, A. \& Masselink, G 2010 'Storm response and beach rotation on a gravel beach, Slapton Sands, U.K', Marine Geology, 278 (1-4), pp. 77-99.

Stockdon, H. F., R. A. Holman, et al. (2006). "Empirical parameterization of setup, swash, and runup." Coastal Engineering 53(7): 573-588. 